\title{
Review and update of the Health of the Nation Outcome Scales for Elderly People (HoNOS65+)
}

\author{
Mick James, ${ }^{1}$ Bill Buckingham, ${ }^{2}$ Gary Cheung, ${ }^{3}$ Roderick McKay, ${ }^{4}$ Jon Painter, ${ }^{5}$ Malcom W. Stewart ${ }^{6}$
}

BJPsych Bulletin (2018) 42, 248-252, doi:10.1192/bjb.2018.68

'Royal College of Psychiatrists, UK; ${ }^{2}$ Australian Government Department of Health, Australia; ${ }^{3}$ University of Auckland, New Zealand; ${ }^{4}$ Health Education and Training Institute, NSW Health, Australia; ${ }^{5}$ Sheffield Hallam University, UK; ${ }^{6}$ Thrive Psychology, New Zealand

Correspondence to Mick James via (Emma.George@rcpsych.ac.uk)

First received 8 May 2018, accepted 3 Jul 2018

(c) The Authors 2018. This is an Open Access article, distributed under the terms of the Creative Commons Attribution-NonCommercial-

NoDerivatives licence (http:// creativecommons.org/licenses/by-ncnd/4.0/), which permits noncommercial re-use, distribution, and reproduction in any medium, provided the original work is unaltered and is properly cited. The written permission of Cambridge University Press must be obtained for commercial re-use or in order to create a derivative work.
Aims and method The Health of the Nation Outcome Scales for Elderly People (HoNOS65+) has been used widely for 20 years, but has not been updated to reflect contemporary clinical practice. The Royal College of Psychiatrists convened an advisory board, with expertise from the UK, Australia and New Zealand, to propose amendments. The aim was to improve rater experience when using the HoNOS65+ glossary by removing ambiguity and inconsistency, rather than a more radical revision.

Results Views and experience from the countries involved were used to produce a series of amendments intended to improve intra- and interrater reliability and improve validity. This update will be called HoNOS Older Adults to reflect the changing nature of the population and services provided to meet their needs. These improvements are reported verbatim, together with the original HoNOS65+ to aid comparison.

Clinical implications Formal examination of the psychometric properties of the revised measure is needed. However, clinician training will remain crucial.

\section{Declaration of interest None.}

Keywords Outcome studies; rating scales; older people's psychiatry.
The Health of the Nation Outcome Scales (HoNOS) was originally developed for use with working-age adults. ${ }^{1}$ Subsequent testing found that, in general, the scales also performed well with older people, but that some adaptations (especially relating to ratings of physical health and cognitive impairment) would be beneficial. ${ }^{2}$ This resulted in the development of the HoNOS65+, ${ }^{3}$ which was validated against other established mental health measures used with older people and shown to have good interrater reliability. ${ }^{3}$ As well as this standardised version, a further version was developed with a tabulated glossary. ${ }^{4}$

Like the HoNOS, the HoNOS65+ was intended to:

- be short and simple for routine use and acceptable to a range of mental health professionals;

- have adequate coverage of clinical and social functions;

- be sensitive to change over time;

- have demonstrable and acceptable reliability;

- have known relationships with more established scales. ${ }^{5}$

Since its development over 20 years ago, the HoNOS65+ has been translated into several other languages, including Spanish, Dutch, French, Greek and Italian, and is now routinely used in clinical practice and research around the world. ${ }^{6}$ Australia and New Zealand have mandated use of the original format of the HoNOS65+ scales for routine monitoring and outcome measurement across their mental health services, ${ }^{7,8}$ while across England both the original version and the more recently developed tabulated version are used to provide these nationally required data. ${ }^{3,4,9}$

Experience of staff training and the evaluation of aggregated data-sets over this period, together with considerable advances in mental healthcare for older people, led to a recognition that the HoNOS 65+ required review and updating. As copyright holder for the HoNOS family of measures, the Royal College of Psychiatrists (RCPsych) elected to undertake a limited review that aimed to use expert opinion to improve the utility of the HoNOS65+ in contemporary older people's mental health services (rather than a full redevelopment and revalidation), while remaining true to its original aims and maintaining comparability with existing data-sets. This paper outlines the scope and process of the review, the issues identified and a revised set of scales (subsequently renamed HoNOS Older Adults).

\section{Method}

In recognition of their nationally mandated use of HoNO S65+, ${ }^{7-9}$ and to ensure that each country's interests were considered, an advisory board (chaired by the RCPsych's National HoNOS Advisor) was convened with 
representatives from England, Australia and New Zealand. Each government nominated individuals with extensive experience in any of the following: HoNOS65+ staff training; using HoNOS65+ in practice; using aggregated HoNOS65+ data; or service-, professional- or governmental-level oversight. In addition to their own views, board members canvased widely for clinicians' opinions regarding which aspects of the HoNOS65+ required refinement.

To ensure consistency with the concurrent HoNOS review, the same criteria were used to judge suggestions. ${ }^{10}$ These criteria were that for a change to be supported, it needed to result in a tangible improvement (e.g. simplification/clarification/removal of anachronisms) and:

- maintain the original instrument's integrity as far as possible;

- maximise comparability with existing individual and aggregated data;

- support the use of HoNOS Older Adults as a summary of clinical assessment(s);

- adhere to the HoNOS65+ 'core rules' i.e.

- each item is a behaviourally anchored five-point scale

$\circ$ items are sequentially rated (1-12)

- all available information is used to make a rating

- information already rated in an earlier item is disregarded

- the most severe problem/worst manifestation from the preceding 2 weeks is rated

- problems are rated according to the degree of distress caused and/or its effects on behaviour

- problems are rated by a mental health professional trained in clinical assessment

- problems are rated regardless of cause.

In addition to these original HoNOS terms of reference, the board was keen to take this opportunity to consider whether there were opportunities to optimise alignment between the newly updated adult and older people's versions. The rationale for this was threefold. First, some of the HoNOS updates had come from the original HoNOS65+. ${ }^{10}$ Second, anecdotal reports suggested that some electronic patient record systems were unable to differentiate between the two versions and/or make both glossaries available to clinicians. Third, since the development of the HoNOS65+, the somewhat arbitrary age cut-off of 65 has become less justified given the increasing variation in functional impairment with age across different populations. ${ }^{11}$

Using the collated feedback and the ensuing board discussions, a summary paper was produced by a board member with extensive experience in old age psychiatry. This highlighted some scales where alignment might be considered a viable option and those where alignment was unlikely owing to the nature of presenting needs in this population. This dictated the sequence of the board's teleconferences and its approach to each scale.

For the scales where alignment was considered to be potentially feasible and likely to improve utility, two questions were asked: first, does it resolve the concerns or problems with the scale reported by old age clinicians in the field; and, second, is the new HoNOS (2018) wording appropriate for older people's mental healthcare? Two positive responses resulted in the revised HoNOS scale being adopted for older people. A negative response led to an iterative process to produce a revised wording that was appropriate for the older people's version of the tool. During this process, consideration was given to whether these proposed changes could also be applied to the draft HoNOS (2018). Where appropriate, to improve both, the draft HoNOS (2018) was aligned with the HoNOS older adult. Where this was not possible, the scale was grouped with items where full alignment had been deemed unfeasible.

For this second group of scales, the board considered both the new HoNOS and the original HoNOS65+ wording in the context of the collated feedback in order to produce a revised HoNOS65+ scale glossary.

\section{Results}

Upon completion of their discussions, the board was able to fully align seven of the 12 scales, with the remaining five having a high degree of similarity but also retaining some key differences. The revised tool (ultimately renamed HoNOS Older Adults) can be seen in Supplementary Table 1, available at https://doi.org/10.1192/bjb.2018.68. Each item's original wording is also included (in greyed-out boxes) to aid comparison.

\section{Discussion}

This publication follows the review of the original (working age) HoNOS. ${ }^{10}$ However, in reality, each review was informed by the other prior to each version of the tool being finalised. As a result, issues specific to older people will be discussed in full below, whereas those common to both tools (and hence previously discussed) will be summarised here purely for completeness. Readers are therefore advised to refer to James et al (2018) to gain an understanding of these common issues.

\section{Overarching rating guidelines}

After reviewing the HoNOS65+ introductory guidance, the board agreed that the issues were identical to those identified with respect to the HoNOS, i.e. that brevity had been prioritised at the expense of clarity. The board also agreed that the newly amended HoNOS guidance was entirely appropriate given that the two tools were intended to function in the same way. Consequently, the same guidance was used, as it:

- clarified the severity threshold between subclinical (0-1) and clinical (2-4) ratings;

- made an overt statement regarding the need for cultural competence on the part of assessors;

- acknowledged the limitations of continuing to use the term 'patient'.

Scale 1: overactive or aggressive or disruptive or agitated behaviour

There was agreement that the issues with this scale were similar, regardless of age, i.e. that:

- raters should be encouraged to consider all four concepts in the title (rather than just focusing on aggression); 
- the issue of culturally sanctioned aggression was now satisfactorily addressed in the preceding, over-arching guidance.

However, some of the original HoNOS65+ examples were felt to be of continued value; hence, those pertaining to the following behaviours were retained:

- restlessness/wandering

- uncooperativeness/resistiveness and the need for persuasion

- sexual disinhibition and deliberate incontinence.

There was some discussion about whether to contextualise inappropriate behaviours (i.e. in public $v$. in private); however, in keeping with the underpinning principles of the scales, it was agreed to simply focus on the behaviour itself. As a result, the two new versions of this scale are broadly similar, but not identical.

\section{Scale 2: non-accidental self-injury}

There was agreement that the issues with this scale were the same regardless of age, i.e. that the new scale should:

- consider risks, thoughts and behaviours

- rely on the over-arching guidance to ensure culturally competent ratings of some forms of ritualistic self-harm.

As a result, the newly revised HoNOS 2018 version of this scale was adopted without amendment.

\section{Scale 3: problem drinking or drug-taking}

There was agreement that the issues with this scale were the same regardless of age, i.e. that the new scale should:

- include descriptors of craving, dependency and behaviour that align with contemporary ratings of severity ${ }^{12}$ and which accommodate rating individuals undergoing shortterm, enforced abstinence;

- omit the subjective concept of 'social norms';

- exclude tobacco use unless it has led to problems over and above the detrimental effects traditionally associated with a person's physical health.

As a result, the newly revised HoNOS 2018 version of this scale was adopted without amendment.

\section{Scale 4: cognitive problems}

After an iterative process of revisions to both the original HoNOS 65+ and the draft HoNOS 2018 versions of this scale, a shared version of the scale was produced. The main issues addressed were therefore:

- the unhelpfully narrow focus on dementia

- the large step between the original ratings of 2 and 3 .

A final review, however, identified the need to retain one example from a rating of 4 on the original HoNOS 65+, i.e. 'consistently unable to recognise or name close friends/family'. As a result, the two versions of this scale are almost, but not absolutely, identical.

\section{Scale 5: physical illness or disability problems}

The new HoNOS 2018 version of this scale was not suitable for older people, and alignment was not deemed viable owing to the effects of age-associated complexities including spectacles and hearing aids, as well as the differing clinical significance of minor falls for the two age groups. Hence, while some text is shared between the new versions of this scale, many of the original HoNOS65+ examples were retained to reduce ambiguity. The two new versions of this scale are therefore notably different.

Scale 6: problems associated with hallucinations and delusions There was agreement that the issues with this scale were the same regardless of age. As a result, the newly revised HoNOS 2018 version of this scale (i.e. limited to minor linguistic changes) was adopted without amendment.

\section{Scale 7: problems with depressed mood}

There was agreement that the issues with this scale were the same regardless of age, i.e. that:

- descriptors should be aligned with the scale's title to remove the current HoNOS65+ contradictions (helpfully, focusing on mood and excluding the wider symptoms of depression also avoided any need to accommodate the differing presentations of depression between the two age groups);

- ratings should include a more balanced description of cognitive, affective and behavioural aspects of low mood (e.g. loss of interest, guilt and low self-esteem) to avoid unduly focusing on feelings of guilt.

As a result, the newly revised HoNOS 2018 version of this scale was adopted without amendment.

\section{Scale 8: other mental and behavioural problems}

There was agreement that the issues with this scale were the same regardless of age, i.e. the need to:

- recognise the dominance of anxiety ratings in this scale, although the creation of a separate scale was deemed to be outside the scope of this work;

- recognise the possibility that rating the most severe problem can lead to a failure to capture less severe issues, while electing to retain this approach;

- add 'elated mood' to the list of options and re-code the options to accommodate this;

- provide additional explanations of each option to improve consistency of ratings.

As a result, the newly revised HoNOS 2018 version of this scale was adopted without amendment.

\section{Scale 9: problems with relationships}

There was agreement that the issues with this scale were the same regardless of age. As a result, the newly revised HoNOS 2018 version of this scale (limited to minor linguistic changes) was adopted without amendment.

\section{Scale 10: problems with activities of daily living}

As with Scale 4, after an iterative process of revisions to both the original HoNOS $65^{+}$and the draft revisions to the HoNOS 2018 version of this scale, a shared version of the scale was produced. The main issue addressed was therefore:

- clarifying how to 'manage' the effects of any existing support the person is receiving. 
A final review, however, identified the need to retain two examples from the original HoNOS 65+. 'Occasional urinary incontinence or continent only if toileted' was therefore included as an example for a rating of 3 , while 'full supervision required with dressing and eating; frequent incontinence' was included to help illustrate a rating of 4 . As a result, the two versions of this scale are almost, but not absolutely, identical.

\section{Scale 11: problems with housing and living conditions}

The new HoNOS 2018 version of this scale was found to be unsuitable for older people, and complete alignment was not deemed viable owing to the need to maintain references to the risks posed to older people by their environment. Removing this feature from the HoNOS65+ was judged to represent a major (and unhelpful) change. Therefore, much of the revised HoNOS 2018 version was adopted, i.e.:

- clarification that the scale is intended to rate how well the person's current environment matches their needs/abilities, not their abilities per se;

- clarification that when rating patients temporarily admitted to hospital their 'usual' place of residence should be considered;

- updates to some of the terminology used.

However, in addition:

- the original HoNOS65+ references to risk were maintained (and, for consistency, introduced to a rating of 1).

- the original HoNOS65+ concept of patient satisfaction was removed owing to potential contradictions between suitability of and satisfaction with housing and living conditions.

As a result, the two new versions of this scale are similar, but not identical.
Scale 12: problems with occupation and activities

There was agreement that the issues with this scale were the same regardless of age, i.e. that there was a need to:

- clarify that the scale is intended to rate how well the person's current environment optimises opportunities to meet their needs or develop their abilities, not their abilities per se:

- clarify that when rating patients temporarily admitted to hospital their 'usual' place of residence should be considered.

- update some of the terminology used.

As a result, the newly revised HoNOS 2018 version of this scale was adopted without amendment.

\section{Other issues}

The advisory board was aware that since the publication of the HoNOS65+ there have been shifts in the well-being of older people, with frailty and disability tending to occur later in life. ${ }^{11}$ With this has also come a shift in the focus of some services for this population. As a result, the existing title, with its focus on the over-65s, was felt to be unhelpful and slightly anachronistic. Increasing the age limit (e.g. to HoNOS 70+) may be more reflective of the group of individuals for whom the tool would be most appropriate in some countries, but still somewhat arbitrary. As a result, it was agreed to rename the scales HoNOS Older Adults, as this would allow clinicians and services to exercise their judgement about when it was appropriate to use each new version of the tool. This could allow the measures to be aligned with variations in the cut-off age for service organisations and practice in different countries and over time. While this variability may have some effect on the comparability of data internationally, it could significantly simplify utilisation of the measures in individual countries.

\begin{tabular}{|ll}
\hline Advisory Board membership & \\
\hline Mick James & National HoNOS Advisor and MHCT Project Manager, RCPsych \\
\hline Prof Mike Crawford & Director of the College Centre for Quality Improvement, RCPsych \\
\hline Adrian Worrell & Head of Centre for Quality Improvement, RCPsych \\
\hline Jon Painter & Joint Clinical Lead, Care Pathways and Packages Project, England \\
\hline Dr Gary Cheung & Senior Lecturer in Psychiatry, Department of Psychological Medicine, University of Auckland, NZ. \\
\hline Dr Clive Bensemann & Director of Mental Health \& Addictions HSG Auckland District Health Board, NZ \\
\hline Dr Arran Culver & Deputy Director Mental Health Ministry of Health, NZ \\
\hline Dr Crawford Duncan & Consultant Psychogeriatrician, Capital and Coast District Health Board, New Zealand \\
\hline Dr Mark Smith & Clinical Lead, Te Pou, NZ \\
\hline Dr Rod McKay & Chair, National Mental Health Information Development Expert Advisory Panel, Australia \\
\hline Mr Tim Coombs & Australian Mental Health Outcomes and Classification Network (AMHOCN)), Australia \\
\hline Ms Rosemary Dickson & AMHOCN and NMHIDEAP Coordinator, Australia \\
\hline Allen Morris-Yates & Director of the Centralised Data Management Service (CDMS), Australia \\
\hline Mr Bill Buckingham & Australian Government Department of Health Technical Advisor (Mental Health), Australia \\
\hline Dr Malcolm W. Stewart & Consultant Psychologist, New Zealand \\
\hline Richard Woodcock & Service and Information Development Manager. Te Pou o te Whakaaro Nui, New Zealand \\
\hline
\end{tabular}


As with the review of HoNOS, ${ }^{10}$ additional areas for development were identified that had merit, but these would have constituted substantial changes and required the development of a completely new instrument. These of course remain an option for future development, pending sector agreement, as well as government interest and funding.

\section{Summary}

The anticipated benefits of these changes should ideally be subject to empirical testing through assessment of interrater reliability and revalidation of the measure in the field. This type of study requires funding and preferably involvement from countries that have heavily invested in the HoNOS65+ to date. This issue is being actively pursued by members of the advisory board

It is also acknowledged that the different jurisdictions involved in the review (and others that have also invested in the use of HoNOS65+) may encounter a range of differing implementation issues. Training programmes in particular are likely to be affected, and while the proposed changes are intended to improve the ease and accuracy of using the scales, it must be stressed that these do not obviate the continued need for training in the use of the scales.

\section{Supplementary material}

Supplementary material is available online at https://doi.org/10.1192/bjb. 2018.68.

\section{About the authors}

Mick James is National HoNOS Advisor at the Centre for Advanced Learning and Conferences, Royal College of Psychiatrists, London, UK; Bill Buckingham is Technical Advisor (Mental Health) at the Australian Government, Department of Health, Canberra, Australian Capital Territory, Australia; Gary Cheung is Senior Lecturer in Psychiatry at the Department of Psychological Medicine, University of Auckland, New Zealand; Roderick McKay, Director Psychiatry and Mental Health Programs, Higher Education and Training Institute, NSW Health, New South Wales Government, Australia; Jon Painter is Senior Lecturer in Mental Health at Sheffield Hallam University, UK; and Malcom W. Stewart is a Consultant Psychologist at Thrive Psychology, Psychology, Auckland, New Zealand.

\section{References}

1 Wing JK, Curtis RH, Beevor AS. Health of the Nation Outcome Scales (HoNOS): glossary for HoNOS score sheet. Br J Psychiatry 1999; 174: 432-4.

2 Turner S. Are the Health of the Nation Outcome Scales (HoNOS) useful for measuring outcomes in older people's mental health services? Aging Ment Health 2004; 8: 387-96.

3 Burns A, Beevor A, Lelliott P, Wing J, Blakey A, Orrell M, et al. Health of the Nation Outcome Scales for elderly people (HoNOS 65+): Glossary for HoNOS 65+ score sheet. Br J Psychiatry 1999; 174: 435-8.

4 HoNOS 65+ Implementing Group. A Tabulated Glossary for Use with the HoNOS 65+. Royal College of Psychiatrists Research Unit, 2004 (https://www.rcpsych.ac.uk/pdf/CECT65\%20Tabulated\%20glossary\% 20v3g.pdf)

5 Wing JK, Beevor AS, Curtis RH, Park SG, Hadden J, Burns A. Health of the Nation Outcome Scales (HoNOS): research and development. Br J Psychiatry 1998; 172: 11-8.

6 Royal College of Psychiatrists. HoNOS 65+ Glossary. Royal College of Psychiatrists, 2018 (http://www.rcpsych.ac.uk/traininpsychiatry/conferencestraining/resources/honos/olderadults/glossary.aspx).

7 Australian Department of Health and Ageing. Mental Health Information Development Mental Health National Outcomes and Casemix Collection: Overview of Clinician-Rated and Consumer Self-Report Measures. Department of Health and Ageing, 2003 (http://www.amhocn.org/ sites/default/files/publication_files/mhnocc_overview_doha.pdf).

8 Te Pou. HoNOS: Guide for New Zealand Clinicians. Te Pou, 2016 (https://www. tepou.co.nz/uploads/files/resource-assets/HoNOS-guide-A4-2016-f.pdf).

9 Department of Health. Mental Health Payment by Results Guidance for 2013-14. Department of Health, 2013(https://www.gov.uk/government/uploads/system/uploads/attachment_data/file/232162/Mental_ Health_PbR_Guidance_for_2013-14.pdf).

10 James M, Painter J, Buckingham B, Stewart MW. A review and update of the Health of the Nation Outcome Scales (HoNOS). BJPsych Bulletin 2018; 42: 63-8.

11 World Health Organization. World Report on Ageing and Health. World Health Organization, 2015 (http://apps.who.int/iris/bitstream/handle/10665/186463/9789240694811_eng.pdf?sequence=1).

12 NICE. Alcohol-use Disorders: Diagnosis, Assessment and Management of Harmful Drinking and Alcohol Dependence. National Institute of Health and Care Excellence, 2011 